\title{
ASPECTOS BIOÉTICOS DA JUDICIALIZAÇÃO DA SAÚDE POR MEDICAMENTOS EM 13 MUNICÍPIOS NO MEIO- OESTE DE SANTA CATARINA, BRASIL
}

\begin{abstract}
Bruna Zago ${ }^{1}$, Liliane Mayumi Swiech ${ }^{1}$, Elcio Luiz Bonamigo², Bruno Rodolfo Schlemper Junior ${ }^{2}$
Resumo: A judicialização na saúde é um fenômeno recente no Brasil, com sérias repercussôes no sistema de saúde público brasileiro. O objetivo deste trabalho foi estudar sua ocorrência em treze municípios de pequeno porte no Meio-Oeste de Santa Catarina, sul do Brasil, no período de 2007 a 2012, analisar os aspectos bioéticos relacionados e propor soluções. Os resultados evidenciaram que, neste período, o valor total/ano das demandas judiciais por medicamentos aumentou quase 10 vezes, beneficiando apenas 175 pacientes, ou $0,134 \%$ dos 129.497 habitantes, ao custo de R $\$ 1.484 .389,92$ (US\$ 740.000). Portanto, pode-se inferir que o atendimento ao princípio da autonomia destes pacientes e do médico, comprometeu, de forma intensa, a equidade e a justa distribuição dos recursos. Conclui-se que este fenômeno, na região estudada, apresenta muitos aspectos semelhantes aos dos grandes centros urbanos, tem sido injusto do ponto de vista dos princípios bioéticos e que a implantaçáo de um Comitê Intermunicipal de Bioética poderia agir como orientador e educador na definição criteriosa da autonomia, equidade e justiça distributiva na alocação dos parcos recursos em saúde. Outros estudos serão necessários para avaliar as consequências da judicialização na saúde no âmbito nacional e encontrar soluçóes eticamente mais adequadas.
\end{abstract}

Palavras-chave: judicialização, bioética, recursos em saúde, equidade na alocação de recursos, medicamentos / provisão $\&$ distribuição

\section{Aspectos bioéticos de la judicialización de la salud por fármacos en 13 ayuntamientos en el Medio Oeste de Santa} Catarina, Brasil

\begin{abstract}
Resumen: La judicialización de la salud es un fenómeno reciente en Brasil, con graves repercusiones para el sistema público de salud brasileño. El objetivo fue estudiar su ocurrencia en trece pequeños ayuntamientos del Medio Oeste de Santa Catarina, sur de Brasil, entre 2007-2012, analizar las cuestiones bioéticas relacionadas y proponer soluciones. Los resultados mostraron que, en este periodo, el total/año de demandas por medicamentos aumentó casi 10 veces, beneficiando solamente 175 pacientes, ó $0,134 \%$ de 129.497 habitantes, con un costo de R $\$ 1.484 .389,92$ (US\$ 740,000). Se puede inferir que el cumplimiento del principio de la autonomía de los pacientes y del médico ha comprometido intensamente la equidad y la justa distribución de los recursos. Se concluye que este fenómeno, en el área de estudio, tiene muchas características similares al de los grandes centros urbanos, ha sido injusto desde el punto de vista de los principios bioéticos y que la implementación de Comité Intermunicipal de Bioética podría actuar como guía y educador en la definición cuidadosa de la autonomía, equidad y justicia distributiva en la asignación de los escasos recursos de salud. Se necesitan más estudios para evaluar las consecuencias de la judicialización de la salud a nivel nacional y encontrar soluciones éticamente más adecuadas.
\end{abstract}

Palabras clave: judicialización, bioética, recursos en salud, equidad en la asignación de recursos, medicamentos / provisión \& distribución

Bioethical Aspects of Health Judicialization for drugs in 13 Municipalities in the Midwest of Santa Catarina, Brazil

\begin{abstract}
Health's judicialization is a recent phenomenon in Brazil, with serious repercussions for the Brazilian public health system. The aim of this work was to study its occurrence in thirteen small towns in the Midwest of Santa Catarina, southern Brazil, in the period of 2007-2012, analyze bioethical issues related and propose solutions. The results showed that, in this period, the total value/year of lawsuits by drugs increased almost 10 times, benefiting only 175 patients, or $0.134 \%$ of 129,497 inhabitants, at a cost of R \$ 1.484.389,92 (US\$740,000). Therefore, it can be inferred that the principle of autonomy of these patients and physician, committed, intensely, the equity and fair distribution of the scarce resources. It was concluded that this phenomenon, in the study area, has many features similar with those of large urban centers, has been unfair from the point of view of bioethical principles and also that the implementation of an Intermunicipal Committee of Bioethics could act as a mentor and educator in the careful definition of autonomy, fairness and justice in the allocation of scarce resources of health. Further studies are needed to assess the consequences of health's judicialization nationally and find solutions more ethically appropriate.
\end{abstract}

Key words: judicialization, bioethics, health resources, equity in the resource allocation, pharmaceutical preparations / supply $\&$ distribution

\footnotetext{
${ }^{1}$ Curso de Medicina da Universidade do Oeste de Santa Catarina - UNOESC, Joaçaba-SC, Brasil

${ }^{2}$ Núcleo de Bioética, Universidade do Oeste de Santa Catarina - UNOESC, Joaçaba-SC, Brasil

Correspondência: schlemper.junior@gmail.com
} 


\section{Introduçâo}

Por judicialização da saúde entende-se a obtenção de procedimentos médicos ou de medicamentos através da via judicial. Esta expressão adquiriu recente relevância pelo grande número de liminares judiciais que obrigam o Município, o Estado ou a Federação a fornecer o solicitado, ocasionando dificuldades financeiras ao setor público devido à escassez de verbas públicas para efetuar tais pagamentos.

O Estado brasileiro mostra-se ineficaz em muitos aspectos da prestação do serviço à saúde da população. Assim, a justiça tornou-se um meio utilizado por aqueles que necessitam de algum procedimento ou medicamento náo oferecido pelo Sistema Único de Saúde (SUS). A Constituição do Brasil(1), de 1988, foi o marco que garantiu à população o direito à saúde e responsabilizou o Estado como o meio efetuador. Por sua vez, a legislação brasileira determina que aproximadamente $12 \%$ dos orçamentos estaduais e $15 \%$ dos municipais sejam destinados à saúde e, destes, uma parcela tem como objetivo a compra de medicamentos. Quando há uma dispensação de medicamentos por via judicial, corre-se o risco de alterar o destino dos recursos financeiros para poucos indivíduos, os quais poderiam destinar-se a muitos cidadãos(2). Ademais, as açôes jurídicas também disputam medicamentos que não estão inseridos na lista fornecida pelo SUS e outros que não têm autorização da Agência Nacional de Vigilância Sanitária (ANVISA) para serem comercializados no Brasil por necessitar de comprovação científica(3).

Os magistrados adotam decisóes baseadas apenas nas prescriçóes médicas, sem uma perícia cautelosa que comprove a necessidade e eficácia do fármaco(4). Esta situação desencadeia uma série de questionamentos bioéticos sobre os limites da autonomia do paciente nas demandas, da utilização do princípio da beneficência pelo médico na prescrição dos medicamentos e da interpretação do princípio da justiça na distribuição de recursos adotada pelo Estado. O volume de recursos destinados à judicialização é táo expressivo que pode causar impacto negativo na gestão pública da saúde(5). Por sua vez, o fenômeno da judicialização não é exclusivo do Brasil, haja vista que muitos países que empreenderam reformas sanitárias em seus sistemas de saúde passaram a incorporar o direito à saúde como um dever de estado, como ocorreu em alguns países latino-americanos que tratam do assunto com muita preocupação. Assim, a questão central que leva os pleitos aos tribunais é o direito à saúde, como constitucionalmente assegurado no Brasil e em muitos outros países(6), sendo que no Brasil o acesso a medicamentos é a principal causa da açáo judicial $(5,7)$.

Neste contexto, tendo em vista a quase ausência na literatura científica de levantamentos em cidades de pequeno porte, a presente pesquisa objetivou estudar, no período de 2007 a 1012, as açóes judiciais impetradas pelos usuários em municípios de baixa densidade populacional da regiáo do Meio-Oeste de Santa Catarina para obtenção de medicamentos. Além disso, foi feita uma discussão sobre os princípios bioéticos aplicados à questão, notadamente sobre a beneficência, autonomia, equidade e justiça e sobre os possíveis mecanismos para resolução das dificuldades vivenciadas pelos médicos, população e gestores.

\section{Metodologia}

A abordagem da pesquisa foi retrospectiva, quali-quantitativa, descritiva e transversal. $\mathrm{O}$ estudo desenvolveu-se no âmbito da Associação dos $\mathrm{Mu}$ nicípios de Meio-Oeste Catarinense (AMMOC), no Estado de Santa Catarina, Sul do Brasil, que é constituída por 13 municípios: Água Doce, Capinzal, Catanduvas, Erval Velho, Herval d'Oeste, Ibicaré, Joaçaba, Lacerdópolis, Luzerna, Ouro, Tangará, Treze Tílias e Vargem Bonita.

As informaçóes sobre os medicamentos foram obtidas da Diretoria de Assistência Farmacêutica (DIAF) da Secretaria Estadual da Saúde de Santa Catarina, por meio dos seguintes dados: município de residência do paciente, data, nome, quantidade e custo do medicamento autorizado pela justiça nos anos de 2007 a 2012. A população trabalhada dos municípios teve como base o censo IBGE 2010, recalculada em 2012. Para uma melhor análise dos medicamentos deferidos pela justiça, os mesmos foram agrupados por classes anatômico-terapêuticas de acordo com a Classificação Anatômica Terapêutica do Anatomical Therapeutic Chemical (ATC), elaborada pela Organização Mundial de Saúde(8). 
Surpreendentemente, há que se registrar os inúmeros obstáculos enfrentados nos órgãos de saúde para a obtenção desses dados, pela negativa sistemática em fornecê-los, sob a alegação de serem informaçóes sigilosas. Porém, os pesquisadores estavam amparados na Lei da Transparência, $\mathrm{n}^{\circ}$ 12.527, de 18 de novembro de 2011(9), que no Brasil assegura aos cidadãos o direito fundamental de acesso à informação e, assim, após interferência do Ministério Público, foi possível obter os dados necessários para a realização do projeto. Os pesquisadores não tiveram acesso aos nomes e às doenças dos pacientes estudados.

Foram calculados os gastos anuais, as porcentagens e o gasto por habitante/ano com a judicializaçáo de medicamentos de cada um e do total de municípios estudados no período pesquisado. Para o estudo da correlação entre o número de habitantes e o gasto com a judicialização foi utilizado o teste de Spearman e o programa estatístico BioEstat 5.0.

\section{Resultados}

Quanto ao tipo de solicitação, nos cinco anos do estudo, todas as 175 demandas judiciais dos 13 municípios eram individuais, impetradas por um único indivíduo e todas foram por receita médica para acesso a medicamentos, não se registrando nenhum pedido para realização de procedimento médico. Estas petiçóes, ao longo dos anos de 2007 a 2012, consumiram $\mathrm{R} \$ 1.484 .389,92(100 \%)$ nos 13 municípios da AMMOC, distribuídos a cada ano, conforme ilustrado na figura 1 .

Figura 1: Gastos anuais (em reais) com medicamentos por açóes judiciais registrados no DIAF, de 2007 a 2012, nos 13 municípios da AMMOC em Santa Catarina, Brasil.

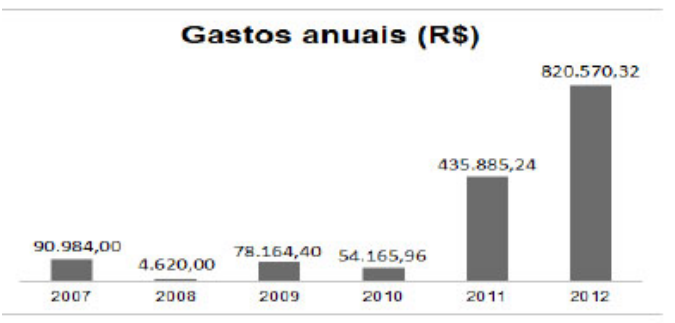

Quanto à participação de cada município, isoladamente, ao longo dos cinco anos, apenas em um deles não foi registrado nenhum pedido judicial, enquanto nos demais, os valores oscilaram de $\mathrm{R} \$$ $3.888,00(0,26 \%)$ até $\mathrm{R} \$ 297.580,68(20,04 \%)$ por município (tabela 1).

Em relação ao gasto/habitante/município com açóes judiciais nos cinco anos, os valores variaram

Tabela 1. Gastos anuais com medicamentos em açôes judiciais registrados entre os anos de 2007 e 2012 nos 13 municípios da AMMOC em Santa Catarina, Brasil.

\begin{tabular}{|l|l|l|l|l|l|l|l|}
\hline \multirow{2}{*}{ Município } & 2007 & 2008 & 2009 & 2010 & 2011 & 2012 & Total \\
\cline { 2 - 7 } & $\mathrm{R} \$$ & $\mathrm{R} \$$ & $\mathrm{R} \$$ & $\mathrm{R} \$$ & $\mathrm{R} \$$ & $\mathrm{R} \$$ & $\mathrm{R} \$$ \\
\hline 1 & 0,00 & 0,00 & 0,00 & 0,00 & 0,00 & $18.432,00$ & $18.432,00$ \\
\hline 2 & $1.440,00$ & $1.440,00$ & 0,00 & $40.884,00$ & $21.528,00$ & $60.498,96$ & $125.790,96$ \\
\hline 3 & $80.640,00$ & 0,00 & $7.200,00$ & 0,00 & $4.956,00$ & $139.680,00$ & $232.476,00$ \\
\hline 4 & 0,00 & 0,00 & $2.217,00$ & 0,00 & $121.434,60$ & $101.660,40$ & $225.312,00$ \\
\hline 5 & $1.608,00$ & $1.080,00$ & $3.240,00$ & 0,00 & $3.024,00$ & $133.071,96$ & $142.023,96$ \\
\hline 6 & 0,00 & 0,00 & 0,00 & 0,00 & 0,00 & $121.434,60$ & $121.434,60$ \\
\hline 7 & $5.136,00$ & $2.100,00$ & $34.043,40$ & $13.281,96$ & $11.988,00$ & $153.331,92$ & $219.881,28$ \\
\hline 8 & $2.160,00$ & 0,00 & 0,00 & 0,00 & 0,00 & $1.728,00$ & $3.888,00$ \\
\hline 9 & 0,00 & 0,00 & 0,00 & 0,00 & $15.768,00$ & $28.497,00$ & $44.265,00$ \\
\hline 10 & 0,00 & 0,00 & $25.200,00$ & 0,00 & $14.317,44$ & $5.040,00$ & $21.877,44$ \\
\hline 11 & 0,00 & 0,00 & 0,00 & 0,00 & $242.869,20$ & $54.711,48$ & $297.580,68$ \\
\hline 12 & 0,00 & 0,00 & $6.264,00$ & 0,00 & 0,00 & $2.484,00$ & $8.748,00$ \\
13 & 0,00 & 0,00 & 0,00 & 0,00 & 0,00 & 0,00 & 0,00 \\
\hline Total & $90.984,00$ & $4.620,00$ & $78.164,00$ & $54.165,96$ & $435.885,20$ & $820.570,32$ & $1.461 .709,92$ \\
\hline
\end{tabular}


Tabela 2. Custo da judicialização de medicamentos por habitante no período 2007 a 2012 nos 13 municípios da AMMOC em Santa Catarina, Brasil.

\begin{tabular}{|l|l|l|l|l|l|l|l|l|}
\hline \multirow{2}{*}{ Município } & Habitantes & 2007 & 2008 & 2009 & 2010 & 2011 & 2012 & $\begin{array}{l}\text { Total do } \\
\text { período }\end{array}$ \\
\cline { 2 - 8 } & & $\mathrm{R} \$$ & $\mathrm{R} \$$ & $\mathrm{R} \$$ & $\mathrm{R} \$$ & $\mathrm{R} \$$ & $\mathrm{R} \$$ & $\mathrm{R} \$$ \\
\hline 1 & 6.979 & 0,00 & 0,00 & 0,00 & 0,00 & 0,00 & 2,64 & 2,64 \\
\hline 2 & 21.064 & 0,06 & 0,06 & 0,00 & 1,94 & 1,02 & 2,87 & 5,97 \\
\hline 3 & 9.746 & 8,27 & 0,00 & 0,73 & 0,00 & 0,50 & 14,33 & 23,85 \\
\hline 4 & 4.365 & 0,00 & 0,00 & 0,50 & 0,00 & 27,82 & 23,28 & 51,62 \\
\hline 5 & 21.420 & 0,075 & 0,05 & 0,15 & 0,00 & 0,14 & 6,21 & 5,67 \\
\hline 6 & 3.341 & 0,00 & 0,00 & 0,00 & 0,00 & 0,00 & 36,34 & 36,34 \\
\hline 7 & 27.467 & 0,18 & 0,07 & 1,23 & 0,48 & 0,43 & 5,58 & 8,00 \\
\hline 8 & 2.203 & 0,98 & 0,00 & 0,00 & 0,00 & 0,00 & 0,78 & 1,76 \\
\hline 9 & 5.605 & 0,00 & 0,00 & 0,00 & 0,00 & 2,81 & 5,08 & 7,90 \\
\hline 10 & 7.348 & 0,00 & 0,00 & 3,42 & 0,00 & 1,94 & 0,68 & 2,98 \\
\hline 11 & 8.653 & 0,00 & 0,00 & 0,00 & 0,00 & 28,06 & 6,32 & 34,39 \\
\hline 12 & 6.568 & 0,00 & 0,00 & 0,95 & 0,00 & 0,00 & 0,28 & 1,33 \\
13 & 4.738 & 0,00 & 0,00 & 0,00 & 0,00 & 0,00 & 0,00 & 0,00 \\
\hline Totais & 129.497 & 0,70 & 0,03 & 0,60 & 0,41 & 3,36 & 6,33 & 11,28 \\
\hline
\end{tabular}

de zero, no município 13 , até $\mathrm{R} \$ 51,62$, no $\mathrm{Mu}$ nicípio 4, com outros três também apresentando valores bastante elevados. Nestes quatro municípios, as populaçôes residentes oscilaram entre 3 mil e 10 mil habitantes (tabela 2).

A média dos gastos totais em judicialização de medicamentos por habitante/ano nos treze municípios do período estudado foi de $\mathrm{R} \$ 0,70$, em 2007; R\$ 0,03 em 2008; R\$ 0,60 em 2009; $\mathrm{R} \$ 0,41$ em 2010; R\$ 3,36 em 2011 e R\$ 6,33 em 2012 (Tabela 2). Por sua vez, a correlação de Spearman (rs) entre o número de habitantes dos municípios e o valor médio gasto em cada um deles apresentou um resultado não significativo $(\mathrm{rs}=0,113 ; \mathrm{p}=0,712)$, traduzindo que o custo médio por habitante nos municípios não se correlaciona com o tamanho de sua população.

O agrupamento dos medicamentos solicitados e autorizados pelo Poder Judiciário, conforme a Classificação por Grupo Anatômico Terapêutico Principal, mostrou os seguintes dados (table 3):

Tabela 3. Medicamentos obtidos por decisão judicial por Grupo Anatômico Principal de acordo com o Anatomical Therapeutic Chemical(8) nos 13 municípios da AMMOC, Santa Catarina, Brasil.

Em relação ao número de medicamentos solici- tados, no período de 2007 a 2012, das 175 açóes judiciais deferidas, a Insulina Glargina, do Grupo Aparelho Digestivo e Metabolismo, foi o medicamento mais requisitado, em 17 ocasióes. Seguiram-se a Prepagalina, com um total de 8 solicitaçóes no grupo do Sistema Nervoso e o Fumarato de Formoterol, com 5 pedidos no grupo do Aparelho respiratório.

\begin{tabular}{|l|l|l|}
\hline Letra & Grupo Anatômico Principal & $\begin{array}{l}\text { Total } \\
\text { autorizado }\end{array}$ \\
\hline A & Aparelho digestivo e metabolismo & 32 \\
\hline B & Sistema nervoso & 22 \\
\hline C & $\begin{array}{l}\text { Agentes antineoplásicos e } \\
\text { imunomoduladores }\end{array}$ & 13 \\
\hline D & Aparelho cardiovascular & 09 \\
\hline E & Medicamentos dermatológicos & 06 \\
\hline F & Sangue e órgãos hematopoiéticos & 07 \\
\hline G & $\begin{array}{l}\text { Anti-infecciosos gerais para uso } \\
\text { sistêmico }\end{array}$ & 04 \\
\hline H & $\begin{array}{l}\text { Preparaçóes hormonais sistêmicas, } \\
\text { excluindo hormônios sexuais e } \\
\text { insulinas }\end{array}$ & 02 \\
\hline I & Sistema músculo-esquelético & 05 \\
\hline J & Produtos antiparasitários & 03 \\
\hline K & Aparelho respiratório & 14 \\
\hline L & Órgãos dos sentidos & 01 \\
\hline M & $\begin{array}{l}\text { Aparelho genito-urinário e } \\
\text { Hormônios sexuais }\end{array}$ & 02 \\
\hline & & \\
\hline
\end{tabular}




\section{Discussão}

O panorama geral da situaçáo atual do fenômeno da judicialização no Brasil pode ser sintetizado da seguinte forma: a) a judicialização no Brasil é um fenômeno crescente e com resultados financeiros elevados, comprometendo os escassos recursos aplicados em saúde; b) Os tribunais estáo sempre com muitos processos para serem julgados e, via de regra, todos são deferidos; c) Todas as demandas judiciais são contra o poder público, nos três níveis de atuação, Federal Estadual e Municipal e, predominantemente, para acesso a medicamentos e, mais raro, por procedimentos ou leitos em Unidade de Terapia Intensiva; d) Este fenômeno, que deveria ser uma exceção, tem se tornado prática diária na busca dos direitos sociais à saúde, decorrente de falhas no Sistema Único de Saúde ou pela falta de regulamentação.

O crescimento destas açóes no Brasil tem sido surpreendente, chegando a índices de $1.878 \%$ de aumento no total de ações deferidas e a $2.156 \%$ no de medicamentos solicitados entre 2003 e 2006, em Santa Catarina(10). No Rio Grande do Sul, de 2002 a 2009, este crescimento foi de $1.412 \%(6)$. Nos 13 municípios catarinenses do presente estudo, observou-se um incremento de, aproximadamente, 10 vezes no período de seis anos. Por sua vez, tanto no presente estudo, quanto em outras pesquisas brasileiras, o pleito dos pacientes é para acesso a medicamentos por parte do Sistema Único de Saúde, variando apenas nos índices $(6,7,11)$. Parece que no Brasil as demandas por medicamentos são mais comuns do que em outros países latino-americanos, nos quais a Colômbia exibiu valores entre $11,9 \%-35,6 \%$, a Costa Rica de 30,2\% e o Brasil de 49,6\%(11).

Uma das grandes dificuldades deste fenômeno é o expressivo número de apelaçóes judiciais de natureza individual, o que assoberba os tribunais no país. Isto ocorreu no presente estudo, no qual todas as demandas foram por apenas um paciente, o que retrata a individualidade das açôes. Reveiz et al.(11) também detectaram isto nos três países latino-americanos estudados (Brasil, Colômbia e Costa Rica), pois a maioria das açóes tinha um único autor. Este fato tem levado alguns $(12,13,14)$ a propor que os juízes estendam suas decisóes para beneficiar a coletividade, pois isto representaria reais avanços em termos de consolidação dos direitos fundamentais pela busca da igualdade e da universalidade no acesso aos bens de saúde e que este tipo de encaminhamento deva ser estimulado. Numa das maiores cidades brasileiras, Belo Horizonte, os gastos com medicação judicial consomem $15 \%$ do total das despesas com medicamentos, o que é comprometedor para o gestor, pricipalmente quando se leva em conta que apenas um pequeno número de indivíduos é beneficiado e que, mais uma vez, os interesses individuais dos beneficiários substituem o coletivo, ocasionando conflitos bioéticos nesta área(15). Continuando nesta linha de abordagem, pode-se argumentar que sendo a saúde um direito de todos, no momento da concessão judicial de um benefício pessoal, é de se supor que sejam ampliadas ainda mais as diferenças entre pessoas na conquista desse direito, ou seja, ferindo a igualdade, a equidade e a justiça distributiva. Isto parece indicar a necessidade de mudança da postura do Poder Judiciário, ressaltando-se a importância para que os tribunais estendam as demandas individuais de modo a atingir todos os que necessitam de determinado bem na região de sua jurisdição. Neste sentido, em recente decisão judicial em Santa Catarina, para uso de stent cardíaco farmacológico, o Ministério Público ingressou com uma Ação Civil Pública solicitando em favor de um determinado paciente e de todos os demais que estivessem precisando. Ao final da tramitação do processo, o requerente já havia falecido e foi oportunizada ao Ministério Público a procura por outros pacientes necessitados(16). Na oportunidade, o Juiz Federal se manifestou da seguinte forma:

"Incumbe-lhe sim, diante da existência de previsão normativa para o tratamento de determinada doença, e da confrontação da prova existente nos autos, decidir em favor da preservação da vida do doente, por isso que a cada cidadáo o tratamento deverá estar acessível nas mesmas condiçôes, sob pena de malferimento à isonomia”.

Há que se ressaltar que, no Brasil, o município é legalmente responsável pela saúde de seus cidadãos, embora os serviços de saúde sejam fornecidos pelo Governo Federal, Estadual e Municipal. Mesmo assim, por ser considerado o último responsável, as ações judiciais são contra o municí- 
pio(15). Nos grandes municípios, os custos conseguem ser pagos por seus gestores, mas naqueles de pequeno porte, como os 13 municípios do Meio Oeste catarinense, os gestores não puderam arcar com os valores necessários e o Governo do Estado se responsabilizou pela cobertura financeira.

Embora os primeiros registros de demandas judiciais por medicamentos no Brasil remontem a meados da década de 90, os resultados encontrados na região estudada, parecem mostrar que este fenômeno é mais recente, provavelmente por serem cidades do interior e com municípios de baixa densidade populacional. Neste sentido, contatou-se que em $21,7 \% \%$ dos processos judiciais analisados de Santa Catarina, em 2003 e 2004, os impetrantes residiam na Capital catarinense e que as demais regióes viriam a ter um rápido crescimento nos próximos anos(17). Resultado idêntico foi encontrado no estado vizinho do Rio Grande do Sul, no qual 20\% das ações analisadas entre 148 municípios pesquisados eram originárias da capital Porto Alegre(6).-

De fato, esta situação foi detectada no presente trabalho, no qual se mostra que a judicialização da saúde na região estudada é muito recente, pois em 2007, dos 13 municípios analisados, apenas cinco já contavam com decisões judiciais. Em 2008, nenhum outro município teve ação judicial, as quais surgiram em 2009, em mais três municípios, em 2011 em mais dois e em 2012, com outros dois municípios, sendo que em um ainda não havia processo judicial no último ano do estudo. Estes dados ilustram que a implantação municipal da judicializaçáo nesta região catarinense foi gradativa, mas que, nos últimos dois anos, houve um crescimento abrupto, com os gastos em 2012 na compra de medicamentos sendo 18.1 vezes maior que em 2010 e cujo pico de crescimento ocorreu em 2011 e 2012. Corroborando estes dados, foi identificada em Santa Catarina uma explosão no número de petiçóes judiciais deferidas que passou de apenas uma, em 2000, para 1.661 em 2006, semelhante à tendência nacional evidenciada pelo Ministério da Saúde do Brasil que classificou o aumento no volume das ações em nível nacional como uma epidemia, com altos e crescentes valores gastos(10)-

Muitos fatores podem influenciar no aumento das demandas de medicamentos via judicial, tais como a facilidade do acesso à informação associada à perspectiva de cura pelo surgimento de novas medicaçôes, a influência do médico e o marketing das indústrias farmacêuticas(7). Estas demandas são favorecidas pela quase impossibilidade do Judiciário negar tais pedidos por se tratar de uma prescrição médica e, portanto, com a presunção de veracidade e a necessidade de cumprir o preceito constitucional de que a saúde é um direito e que cabe ao Estado o dever de supri-la.

Por sua vez, quando se analisa o valor médio por paciente das açóes judiciais deferidas no presente estudo, encontrou-se um valor correspondente a $\mathrm{R} \$ 8.346,00$, bem inferior ao registrado em São Paulo, cuja média foi de, aproximadamente, 18 mil reais por paciente com açóes judiciais em 2006(18). Esta diferença pode ser explicada pela maior demanda por medicamentos de alto custo e até mesmo por drogas importadas nos grandes centros urbanos.

Um resultado que chamou a atenção no presente estudo foi a diferença de gasto em judicialização, por habitante, entre os municípios no período estudado. $\mathrm{O}$ município 4 teve a maior média de gastos por habitante ( $\mathrm{R} \$ 51,62)$, seguido dos municípios 6 e 11 cujos custos por habitante foram $\mathrm{R} \$ 36,35$ e $\mathrm{R} \$ 34,40$, respectivamente. Em contrapartida, os municípios 8, 12 e 13 apresentaram um gasto inferior a $\mathrm{R} \$ 2,00$ por habitante. Estas diferenças expressivas foram decorrentes da prescrição por alguns medicamentos considerados de alto custo pelo Sistema Único de Saúde, como o interferon peguilado, anticorpos monoclonais (Transtuzumab), Deferasirox, Etanercept, Erlotinibe e outros, os quais atendem as necessidades mínimas de poucos indivíduos e a um custo muito elevado. Em Florianópolis, 77\% dos custos dos medicamentos judiciais foram gastos com agentes antineoplásicos e imunomoduladores, entre 2000 e 2006(10).

Entretanto, observa-se que o valor gasto por habitante/ano da região estudada com a judicialização da saúde aumentou vigorosamente nos últimos anos, variando de $\mathrm{R} \$ 0,70$, em 2007, para a elevada cifra de $\mathrm{R} \$$ 6,33 reais em 2012. Este aspecto sinaliza para a inadequada aplicação do princípio bioético da justiça por serem poucos os favoreci- 
dos em detrimento de muitos, fato este que torna mais evidente a iniquidade já existente(19). O valor de $\mathrm{R} \$$ 6,33 reais per capita, em 2012, é relativamente alto quando se considera que muito poucos foram beneficiados e que o Ministério da Saúde do Brasil(20) repassa aos gestores da saúde para a aquisição de medicamentos, somente $\mathrm{R} \$$ 5,10 habitante/ano, ao qual são acrescidos $\mathrm{R} \$$ 1,86 dos Estados e Municípios, totalizando R \$ 8,82 habitante/ano.

Outro aspecto a ser especialmente considerado é o aumento da autonomia do paciente em sua relação com o médico assistente. O Código de Ética Médica do Brasil(21) apresenta, em seu Capítulo I, no Princípio XXI dos Princípios Fundamentais, a seguinte orientação: "No processo de tomada de decisóes profissionais (...) o médico aceitará as escolhas de seus pacientes, relativas aos procedimentos diagnósticos e terapêuticos por eles expressos, desde que adequadas ao caso e cientificamente reconhecidas". Assim, após serem oferecidos os esclarecimentos, a autonomia dos pacientes deve ser respeitada pelo médico assistente. No entanto, muitas vezes o paciente deseja uma terapia em experimento e de altíssimo custo para prolongar muito pouco sua sobrevida. Como a saúde é um direito da população e dever do Estado, assegurado pelo artigo 196 da Constituiçáa Federal do Brasil(1), este acaba por arcar com os custos que são demandados através de processo judicial e concedidos na quase totalidade das vezes.

Um segundo aspecto a ser analisado é a aplicação do princípio bioético da justiça na distribuição de recursos. Quem padece de uma doença grave, precisa de mais recursos do que aquele que pouco ou nada apresenta. Neste aspecto, Villas-Bôas(22) ressalta que o princípio da equidade tem o objetivo de proporcionar recursos desiguais aos desiguais, como proposto por John Rawls(23) em sua Teoria da Justiça. No entanto, para beneficiar a saúde da população faz-se necessária a distribuição de recursos de forma igualitária, evitando-se que poucos sejam beneficiados em detrimento da maioria(24). Para tanto, deve haver uma gestão eficiente dos recursos disponíveis, fazendo com que o sistema de cuidados de saúde seja acessível, de qualidade e eficiente do ponto de vista custo-benefício. No entanto, um sistema para ser eficiente deveria ser também equânime, evitando exclusóes por idade e local de residência ou limitaçôes por indisponibilidade de centros de tratamento(25).

No entanto, as escolhas pessoais amparadas na autonomia do paciente podem constituir um fator de complicação para a justa distribuição de recursos, especialmente nos países em permanente contingenciamento orçamentário. Gargarella (26) menciona uma interessante crítica feita por Gerald Cohen à teoria da justiça de John Rawls em que as escolhas pessoais também deveriam ser justas para que a justiça seja alcançada. Contudo, se as reivindicaçôes concedidas não forem justas, haverá prejuízos à distribuição de recursos por falha na aplicação do princípio da justiça. Neste sentido, parece haver uma lógica adversa pois, se por um lado, as decisóes judiciais garantem o atendimento ao direito e às necessidades do cidadáo, por outro, remetem ao gestor a responsabilidade de decisões administrativas, que muitas vezes contradizem os princípios constitucionais da equidade e do acesso à saúde de qualidade por não serem apoiadas em princípios bioéticos(27). Esta observação permite inferir que o respeito estrito à autonomia do paciente na concessão do benefício, pode trazer, no bojo dos escassos recursos dos países em desenvolvimento, uma injustiça no que diz respeito ao não atendimento das mesmas necessidades de expressivo número de pessoas. Em outras palavras, a persistir o atual comportamento da Justiça de atendimento às necessidades individuais, sem a justa extensão do benefício aos demais portadores da mesma carência, as decisóes continuarão a ampliar a injustiça e a equidade. Portanto, entende-se que deve ser levar em conta que a real escassez de recursos e as necessidades individuais serão sempre maiores do que o orçamento público, razão pela qual, escolhas devem ser feitas, pois não é possível prover todos os direitos sociais em grau máximo a todas as pessoas (14). Ou, ao invés de garantir o direito a determinadas pessoas, a judicialização poderia estar contribuindo para intensificar a assimetria de direitos entre os indivíduos(3).

No período estudado, um total de 116 medicamentos foi solicitado por via judicial, sendo que $30(25,8 \%)$ deles faziam parte da lista dos fármacos fornecidos pelo Sistema Único de Saúde nos 13 municípios catarinense, enquanto para toda 
Santa Catarina, entre os anos de 2000 a 2006, $29 \%$ dos medicamentos eram padronizados por algum programa governamental estadual ou federal(10). Em princípio, estas drogas deveriam estar disponíveis aos pacientes na rede pública de atenção à saúde. Levanta-se a hipótese de que, melhorando a gestão da assistência farmacêutica, este tipo de demanda judicial tende a se concentrar nos medicamentos não fornecidos pelo SUS, sobretudo, os de alto custo, fazendo decrescer as demandas(28). Neste aspecto, uma reunião nacional de secretários da saúde, realizada em 2004, apontou como causas de demandas judiciais a falta de medicamentos, o descumprimento de protocolos já existentes e os medicamentos sem registro na ANVISA ou de eficácia não comprovada(29). Desta forma, a indisponibilidade de medicamentos, que deveriam estar acessíveis, e a força da prescrição médica, são apontadas como causas da judicialização.

Os elevados valores gastos com a judicialização na saúde na região estudada suscitam a necessidade de discussão dos princípios bioéticos, com ênfase para o princípio da justiça cujo objetivo é beneficiar equitativamente o maior número de pessoas possível. No contexto da Administração Pública, a adoçáo de medidas especiais para a melhoria da assistência farmacêutica, reservaria o recurso da judicialização somente para casos excepcionais. No entanto, o direito à saúde é tido como um direito fundamental à preservação da vida e dignidade humana(7). A promoção da justiça em municípios em que os recursos para a saúde são escassos é uma tarefa bastante complexa para ser colocada em prática, como ficou demonstrado neste trabalho, no qual o valor gasto por habitante em judicializaçáo foi bastante elevado, aproximando-se do valor total dos recursos per capita provisionados pelo Ministério da Saúde para medicamentos visando ao atendimento de toda a populaçáo. Sobre este assunto, na aplicação do princípio da justiça em recursos escassos, eventualmente, seria possível negar certos medicamentos de alto custo e com falta de eficácia quando não há risco de morte para o paciente(30). Entende-se que esta contingência abarca a negativa de medicamentos solicitados sem critérios adequados e sem análise do custo-benefício.

O paciente tem total liberdade e autonomia para buscar seu bem individual, por não ser sua a responsabilidade pela preservaçáo do bem coletivo. A seu favor está o médico cujo compromisso ético é com a beneficência de seu paciente, não estando ao seu encargo a responsabilidade pela promoçáo da justiça distributiva(31). Nesse aspecto o Código de Ética Médica(21, p.39), no Inciso II do Capítulo II, garante ao médico o direito de "indicar o procedimento adequado ao paciente, observadas as práticas cientificamente reconhecidas e respeitada a legislação vigente". Sua prescrição, amparada pelo princípio da beneficência, constitui o principal fundamento utilizado pelo judiciário para o atendimento das demandas dos pacientes. Todavia, deve ser aventado que a prescrição médica tanto pode ser muito eficiente e adequada como não ser técnica e cientificamente aceitável(32). Porém, em muitos casos, as prescriçôes médicas contêm escassas informaçóes sobre o quadro clínico ou o diagnóstico da doença, mas, mesmo assim, as açóes são sempre garantidas pelos tribunais. Se o paciente não é o responsável pela justiça na aplicação dos recursos, o médico deve preocupar-se com a beneficência do paciente e o judiciário tende a acatar a prescrição do médico, a solução para o crescimento vertiginoso da judicializaçấo pode estar na formação de Comitês Intermunicipais de Bioética que venham a contribuir para o adequado planejamento e distribuição dos recursos em saúde(33).

Neste aspecto, num estudo de 27 casos observou-se que náo havia relatório médico em nenhum e que somente em dois havia exames complementares comprobatórios das doenças(34). Estes dados servem de alerta aos médicos sobre sua responsabilidade ética na emissão de receitas para uso de medicamentos. Por sua vez, o surgimento de novas drogas e muitos tratamentos experimentais possibilita que vultosas quantias sejam despendidas com tratamentos de eficácia duvidosa obtidos judicialmente.

\section{Conclusão}

Durante os anos 2007 a 2012 ocorreu um considerável avanço das demandas judiciais por medicamentos no âmbito da Associação de Municípios do Meio-Oeste Catarinense, sobretudo nos anos 2011 e 2012. Esse abrupto aumento mostrou que o fenômeno da judicialização é muito recente e 
agudo na região estudada. $\mathrm{O}$ desequilíbrio na distribuição de recursos oriundos deste fenômeno ficou evidente na medida em que, no período estudado, o gasto por habitante variou de zero, em um dos municípios, para $R$ \$ 51,62 reais no município em que mais ocorreram demandas. $\mathrm{O}$ aumento das demandas judiciais por medicamentos, de um lado, beneficia os pacientes e, de outro, pode acarretar o desequilíbrio financeiro dos municípios, uma vez que o direito individual afeta o bem coletivo. Este desequilíbrio tem o potencial de produzir maior desigualdade na distribuição de verbas. Acrescente-se que o valor por habitante gasto com a judicialização de medicamentos na regiáo estudada quase alcançou o valor total previsto pelo Ministério da Saúde para cada cidadão brasileiro. Ainda, a pesquisa mostrou que a judicializaçáo da saúde nos 13 municípios de pequeno porte estudados mantém características muito semelhantes com o ocorrido nos grandes centros urbanos brasileiros, como uma rápida e vigorosa expansão, predomínio absoluto por acesso a medicamentos, individualização das açôes judiciais com possíveis prejuízos ao restante da população, pedidos judiciais por fármacos de alto custo e fração razoável de medicamentos disponibilizados pelo sistema público de saúde. Porém, o fato mais perverso destas açóes nos municípios pequenos é o drama vivenciado pelos responsáveis pela gestão da saúde municipal no enfrentamento dos dilemas éticos da autonomia do paciente, da equidade e da justiça distributiva.

Em decorrência, como os médicos, gestores e população não foram capacitados a enfrentar esta nova situação, resgata-se a importância de implantaçáo de comitês intermunicipais e multiprofissionais de Bioética, os quais contando com suporte de instituições universitárias poderiam contribuir com melhor aplicação destes princípios bioéticos na distribuição dos escassos recursos para a saúde(33). Estudos mais amplos serão necessários para avaliar a dimensão da judicialização em todo o país e apontar soluçóes, tendo em vista ser a judicialização da saúde um fato relativamente novo e por envolver vários e diferenciados interesses, assim como diferentes estruturas de Poder do Estado.

\section{Agradecimentos}

Este estudo foi financiado pelo Programa de Bolsa de Iniciação Científica instituído pela Lei Complementar no 281/05, que regulamenta o artigo 170 da Constituição Estadual do Estado de Santa Catarina.

Referências

1. Brasil. Constituição da República Federativa do Brasil. Brasília, DF: Senado; 1988.

2. Tanaka OY. A Judicialização da Prescrição Medicamentosa no SUS ou o Desafio de Garantir o Direito Constitucional de Acesso à Assistência Farmacêutica. Revista de Direito Sanitário 2008; 9(1): 137-143.

3. Machado FRS. Contribuiçôes ao Debate da Judicializaçâo da Saúde no Brasil. Revista de Direito Sanitário 2008; 9(2); 73-91.

4. Bonfim JRA. Demandas judiciais por fármacos no sistema único de saúde: direitos dos pacientes e provas científicas para se realizar o acesso. In: Keinert TMM, Paula SHB, Bonfim JRA. As açöes judiciais no SUS e a promoção do direito a saúde. São Paulo: Leitura Médica Ltda.; 2009: 139-156.

5. Marques SB. Judicialização do Direito à Saúde. Revista de Direito Sanitário 2008; 9(2): 65-72.

6. Biehl, J, Amon JJ, Socal MP, Petryna A. Between the court and the clinic: Lawsuits for medicines and the right to health in Brazil. Health Human Rights 2012; 4(1): E36-52.

7. Ventura M, Simas L, Pepe VLE, Schramm FR. Judicialização da saúde, acesso à justiça e a efetividade do direito à saúde. Physis Revista de Saúde Coletiva 2010; 20(1): 77-100.

8. World Health Organization. Collaborating Centre for Drug Statistics Methodology. Guidelines for ATC (Anatomical Therapeutic Chemical) classification system and DDD (Defined Daily Dose) assignment 2013 (online). Oslo; 2013 (cited 2013 may 31). Available from: URL: http://www.whocc.no/filearchive/publications/1_2013guidelines.pdf

9. Brasil. Lei no 12.527 de 18 de novembro de 2011. Regula o acesso à informação. Diário Oficial da União 16-5-2012 e retificado em 18.5.2012.

10. Boing AC. Política e Constituição: a judicializaçâo do acesso a medicamentos em Santa Catarina (dissertação). Itajaí; 2008. 
Aspectos bioéticos da judicialização da saúde por medicamentos - Bruna Zago et al.

11. Reveiz L, Chapman E, Torres R, Fitzgerald JF, Mendoza A, Bolis M, et al. Litigios por derecho a la salud en tres países de América Latina: revisión sistemática de la literatura. Revista Pan-americana de Salud Pública 2013; 33(3): $213-222$.

12. Fleury S. Judicialização pode salvar o SUS. Saúde em Debate 2012; 36(93): 159-162.

13. Barroso, LR. É preciso transformar açôes individuais em coletivas. Revista Consultor Jurídico (online) 2009; (cited 2013 may 31). Available from: URL: www.conjur.com.br/2009-mai-06/barroso-aponta-solucao-racionalizar-judicializacaosaude

14. Swiech LM, Schlemper Júnior BR, Bonamigo EL, Zago B. Aspectos bioéticos da judicialização na saúde. In: Silva J, Bonamigo EL. Bioética: pontos de mutação de uma sociedade em mudanças. São Paulo: All Print; 2013: 133-152.

15. Menicucci TMG, Machado JA. Judicialization of Health Policy in the Definition of Access to Public Goods. Brazilian Political Science Review 2010; 4(1); 33-68.

16. Justiça Federal do Estado de Santa Catarina (Brasil). Comarca de Blumenau, Santa Catarina. Ação Civil Pública no 5007289-43.2012.404.7205 (online) 2013 (cited 2013 may 31.

17. Pereira Júnior, Santos RI, Nascimento Junior JM do, Schenkel EP. Análise das demandas judiciais para o fornecimento de medicamentos pela Secretaria de Estado da Saúde de Santa Catarina nos anos de 2003 e 2004. Ciência \& Saúde Coletiva 2010; 15(Supl. 3): 3551-3560.

18. Chieffi AL, Barata RB. Judicialização da política pública de assistência farmacêutica e equidade. Cadernos de Saúde Pública 2009; 25(8): 1839-1849.

19. Diniz D, Medeiros M, Schwartz IVD. Consequências da judicialização das políticas de saúde: custos de medicamentos para as mucopolissacaridoses. Cadernos de Saúde Pública 2012; 28(3): 479-489.

20. Ministério da Saúde. Assistência Farmacêutica. Relação Nacional de Medicamentos quase dobra (online) 2012; (cited 2013 may 31). Available from: URL: http://portalsaude.saude.gov.br/portalsaude/noticia/4603/162/relacao-nacionalde-medicamentos-quase-dobra.html

21. Conselho Federal de Medicina. Código de Ética Médica: Resoluçâo CFM no 1.931, 2009 (versão de bolso). Brasília; 2010.

22. Villas-Bôas ME. Justiça distributiva, critérios de alocação de recursos escassos em saúde e suas críticas. Revista Rede bioética/UNESCO 2010; 1(2): 73-84.

23. Rawls J. Teoría de la Justicia. 2a ed. México: Fondo de Cultura Económica; 2006.

24. Montes CL, Ugás AG. El Principio de Justicia y la Salud en Chile. Acta Bioethica 2008; 14(2): 206-211.

25. Fajuri AZ. Justicia y racionamiento sanitario en el Plan AUGE: dilemas bioéticos asociados a la distribución de recursos escasos. Acta Bioethica 2011; 17(1): 73-84.

26. Gargarella R. As teorias da justiça depois de Rawls. Um breve manual de filosofia política. São Paulo; 2008.

27. Andrade EIG, Machado CD, Faleiros DR, Szuster DAC, Guerra Júnior AA, Silva GD, et al. A judicialização da saúde e a política nacional de assistência farmacêutica no Brasil: gestão da clínica e medicalização da justiça. Revista Médica de Minas Gerais 2008; 18(4): S46-S50.

28. Pepe VLE, Ventura M, Santana JMB, Figueiredo TA, Souza VDR, Simas L, Castro CGSO. Caracterizaçâo de demandas judiciais de fornecimento de medicamentos “essenciais” no Estado do RJ, Brasil. Cadernos de Saúde Pública 2010; 23(6): 461-471.

29. Machado MAA, Acurcio FA, Brandão CMR, Faleiros DR, Guerra Júnior AA, Cherchiglia ML, Andrade EIG. Judicialização do acesso a medicamentos no Estado de Minas Gerais, Brasil. Revista de Saúde Pública 2011; 45(3): 590-598.

30. Cortina A, Martínez E. Ética. 2a ed. São Paulo: Edições Loyola; 2009.

31. Gracia D. Fundamentos de Bioética. Coimbra: Ethica; 2007.

32. Scheffer, M. Judicialização e incorporação de tecnologias: o caso dos medicamentos para tratamento da Aids no sistema único de saúde. In: Keinert TMM, Paula SHB, Bonfim JRA. As açôes judiciais no SUS e a promoção do direito a saúde. São Paulo: Leitura Médica Ltda.; 2009: 129-138.

33. Petry P, Conte K, Bonamigo EL, Schlemper Júnior BR. Comitê de Bioética: uma proposta para a atenção básica da saúde. Bioethikos 2010; 4(3): 258-268.

34. Sant'Ana JMB, Pepe VLE, Figueiredo TA, Osorio de Castro CGS, Ventura M. Rational therapeutics: health related elements in lawsuits demanding medicines. Revista de Saúde Pública 2011; 45(4): 1-8.

Recebido: 2 de junho de 2013

Aceito: 24 de março de 2014 